\title{
Current and Potential Relations for the Cathodic Protec- tion of Steel in a High Resistivity Environment
}

\author{
W. J. Schwerdtfeger
}

(March 23, 1959)

\begin{abstract}
In order to evaluate potential and current criteria for the cathodic protection of bare low-carbon steel in a high-resistivity environment, specimens were exposed in the laboratory for a period of two months to a soil having a resistivity of about 20,000 ohm-centimeter.

Previous work in low-resistivity environments by the author and by other investigators has shown that corrosion can be reduced to a negligible degree by polarizing a steel structure to -0.85 volt (protective potential) with reference to a copper-copper sulfate electrode. In such studies by the author, cathodic polarization curves have also been shown to be useful in indicating the current density required for cathodic protection.

In the present study the above criteria were again evaluated. In addition to protecting the steel at the protective potential (free of $I R$ drop), the effect on protection of including $I R$ drop caused by the protective current was also noted. Also, cathodic polarization curves were obtained on a recorder in conjunction with a bridge circuit to eliminate the $I R$ drop.

The results show that the best degree of protection was achieved on the specimen controlled at -0.77 volt (without $I R$ ) with reference to a saturated calomel half-cell. This is approximately equivalent to the protective potential -0.85 volt with reference to the copper-copper sulfate electrode. Applied current indicated by the break (change-in-slope) in the cathodic polarization curve agreed reasonably well with the actual current necessary to maintain polarization at -0.77 volt (free of $I R$ ).

The current required for protection was about three times the magnitude of the corrosion current; therefore, the corrosion reaction was either under anodic control (unlike previous studies) or an equivalent type of control which was caused by high resistance at anodic areas.
\end{abstract}

\section{Introduction}

Studies of cathodic protection previously carried out in the laboratory at the National Bureau of Standards were all conducted with soils and waters having resistivities less than $1,000 \mathrm{ohm}-\mathrm{cm}$. The experiments showed that the protective potential $-0.77 \mathrm{v}$ with reference to the saturated calomel halfcell (equivalent to $-0.85 \mathrm{v}$ with reference to the copper-copper sulfate electrode), when free of $I R$ drop caused by the protective current, was effective in preventing appreciable loss of metal on steel specimens $[1,2] .^{1}$ Corrosion processes were found to be controlled chiefly by cathodic reactions, and cathodic polarization curves were shown to be very useful in indicating the currents necessary to produce adequate polarization and virtually complete protection.

It was suggested by Sudrabin and Ringer, [3] as a result of some of their recent work, that useful information would be obtained if studies were continued in high-resistivity environments where corrosion rates are controlled largely by electrolytic resistance, rather than by polarization alone. Further research was suggested by the National Association of Corrosion Engineers Unit Committee (T-2C) [4] on "Criteria for Cathodic Protection" under which some task groups have been assigned to: (a) Examine basic criteria that can be used for determining the adequacy of cathodic protection, or (b) promote research and technical papers on criteria for cathodic protection.

${ }_{1}$ Figures in brackets indicate the literature references at the end of this paper.
In high-resistivity environments in the field, measured potentials often include considerable $I R$ drop as well as polarization voltage resulting from the protective current. As the $I R$ drop caused by the applied current within the cathodic branch of a corrosion cell assists in reducing the corrosion cell current, the question arises as to what extent $I R$ drop can be tolerated under practical circumstances, for example, in potential measurements made on pipelines.

Cathodic polarization curves are generally recognized as being useful in estimating the current density required for cathodic protection when corrosion reactions are controlled by cathodic polarization(cathodic control). However, there is a question regarding their usefulness when the corrosion current is determined mainly by anodic polarization (anodic control), or when the resistance of the electrolyte (high resistivity) is a limiting factor along with polarization.

The study to be described was conducted by exposing low-carbon steel specimens to a soil (sandy loam) having a resistivity of about 20,000 ohm-cm. In such a high-resistivity environment, it was presumed that the $I R$ drop between the reference electrode and the specimen would probably be greater than the polarization voltage and thereby present the opportunity of evaluating the effect of each factor. Preliminary laboratory experiments revealed that cathodic polarization did not take place as readily as in low-resistivity environments and that the currents required for protection were larger than anticipated. This suggested a divergence from the usual cathodic type of control. 


\section{Experimental Procedure}

\subsection{General Procedures}

All specimens were cut from one piece of colddrawn steel tubing ( 1 in. o.d. by 0.125 in. wall thickness) to lengths of $8 \mathrm{in}$. The tubes were degreased with carbon tetrachloride and the ends rounded so as to be without burrs. The inner and outer surfaces of the tubes were wire-brushed, smoothed with $1 \mathrm{G}$ emery paper, washed in hot water, and then weighed to the nearest milligram. A rubber-covered stranded copper wire was soldered to one end of each specimen for the electrical connection. A coating of oil was flowed over the inside surface of each tube and both ends plugged with rubber stoppers. A heavy coating of bitumastic was applied over the edges of the tube, covering the wire and soldered connection, insuring a moisture seal around the stopper and leaving $24 \mathrm{in}^{2}$ of cylindrical surface for exposure to the soil.

The soil, a sandy loam from Lanham, Md., after being removed from the field, was air dried and sifted using a No. 10 sieve. Preliminary measurements of soil resistivity versus moisture content were made in order to determine a moisture range which provided a fairly stable soil resistivity without saturating the soil. A satisfactory amount of water was found to be about 15 percent by weight of the dry soil. By adding distilled water to the soil this moisture content resulted in a soil resistivity of about $20,000 \mathrm{ohm}-\mathrm{cm}$ at $80^{\circ} \mathrm{F}$.

Five specimens were used in the experiment, two of which were without cathodic protection, serving as controls, while the other three had currents applied. Exposure to the soil was for a period of 61 days. Four Pyrex jars were used to hold the soil, the two controls being placed in one jar. The soil was moistened in four batches of equal weight, one batch for each jar. The wetting procedure was carried out by slowly adding water to the soil, mixing, adding more water, mixing again, et cetera.

A high-purity zinc rod $(0.0375$ in. diam by 10 in. long) was permanently exposed to the soil of each jar for use as a reference electrode. Continual or even intermittent ordinary use of an agar-salt bridge to a saturated calomel half-cell would have greatly lowered the soil resistivity. Thus, contact of the soil with an agar-salt bridge was limited to about 10 sec each day in order to measure the potential of the zinc electrode so that the specimen potentials, either measured or controlled, with reference to the zinc could be converted to the saturated calomel scale.

After 61 days of exposure to the soil the specimens were removed for cleaning and measurement of metal loss. The corrosion products, which were very adherent, were loosened by cathodic cleaning for $2 \mathrm{hr}$ at a current density of $1 \mathrm{amp} / \mathrm{ft}^{2}$ in a $10-$ percent solution of ammonium citrate neutralized with ammonium hydroxide. This was followed by scrubbing with a brass bristle brush under hot water. The oil preserved the inner surfaces of the tubes from corrosion. The soldered wire connection was removed by applying heat from a soldering iron and the last bits of solder were removed by scraping with a soft metal tool. Finally all specimens were again rinsed in hot water, blown dry with compressed air, and weighed.

\subsection{Arrangement for Exposure}

Cross-sectional views of the setup for exposure are shown in figure 1. Two cylindrical Pyrex jars were used, the inner one ( 8.75 in. o.d. by $10 \mathrm{in}$. high) containing the soil, steel specimen and auxiliary electrodes, and an outer jar (12 in. o.d. by 12 in. high) containing the smaller jar resting in distilled water about 1 in. deep. The outer jar was covered with a loose-fitting inverted pan which helped to control the moisture content of the soil and yet permitted entrance of air. Wires (not shown) from the specimen, zinc reference rod, and steel anodes were brought outside over the edge of the jar slightly tilting the cover as shown. These wires were fastened to the outer wall of the jar.
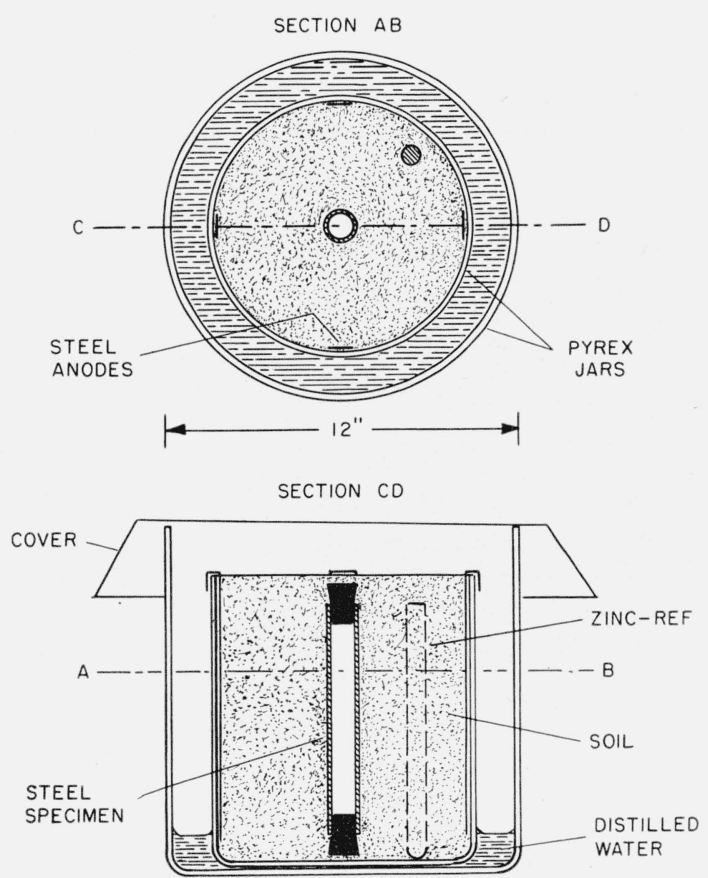

Figure 1. Cross-sectional views of the experimental arrangement for exposing specimens to the soil.

The specimen and the zinc rod were separated by about $2 \frac{3}{4}$ in. of soil, with $\frac{1}{2}$ in. of soil between the zinc and jar wall. Four anodes, consisting of strips of sheet steel (1.5 in. wide) running from top to bottom, were interconnected by soldered wires. The surfaces of the anodes adjacent to the glass were covered with insulating tape. Wet soil, prepared as previously described, was packed uniformly around the electrodes. As previously mentioned, the control specimens were both in the same jar. One was centrally located as shown in figure 1 and the other was in line with the center specimen and the zinc rod and on the side opposite the zinc rod. One 
inch of soil separated the off-center specimen from the jar wall, the axes of the specimens being parallel to each other.

\subsection{Instrumentation}

Currents were applied to three of the specimens for the entire exposure period. The criterion of cathodic protection for the first specimen was the current adjusted in accordance with values from cathodic polarization curves obtained on the controls. The criterion of protection for the second specimen was the potential $-0.77 \mathrm{~V}$ (reference saturated calomel electrode) free of $I R$ drop. Protection of the third specimen was also based on the potential $-0.77 \mathrm{v}$, except that the potential included the $I R$ drop between the specimen and the reference electrode caused by the externally applied current.

The circuit used for obtaining polarization curves and for measuring potentials free of $I R$ drops is shown in figure 2, the bridge being basically that described by Holler [5]. Resistors Q and D were each 100,000 ohms and the variable resistor, $\mathrm{X}$, was used for balancing out the $I R$ drop between the specimen and the reference electrode (zinc). When the bridge was balanced, the actual potential of the specimen was equal to twice the indicated or recorded value. A balanced bridge was indicated by no movement of the recorder pen when the current applied to a specimen was momentarily interrupted. Too small or too large a value of resistance $\mathrm{X}$ would cause the pen to suddenly shift in one direction or the other when the applied current was interrupted, but movement of the pen due to changes in polarization emf were relatively minor.

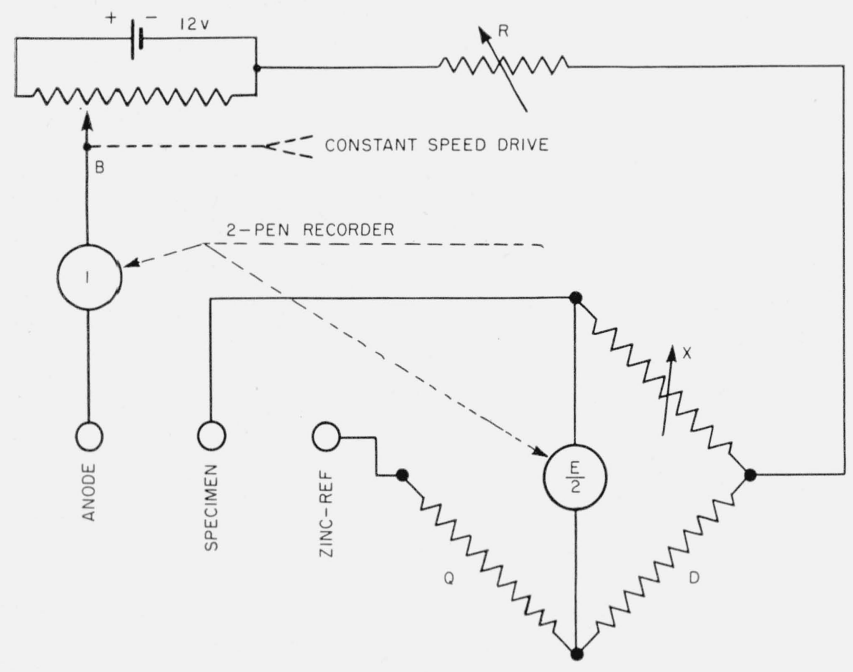

FIgure 2. Circuit for obtaining polarization curves automatically and for measuring potentials of specimens free of IR drops.

One recorder pen indicated current and the other potential.
The procedure followed for measuring potentials (without $I R$ ) of the three specimens under protection was to first measure the current to a specimen and then, without interrupting the current, to transfer the specimen to the voltage supply associated with the bridge circuit, which was preadjusted to furnish the same current. Before reading the potential, the setting of resistor $\mathrm{X}$ was checked for bridge balance as described in the previous paragraph or by simply varying resistor $\mathrm{X}$ by fixed amounts, above and below the set value, until equal left and right deflections of the potential pen were in evidence.

Cathodic polarization curves were recorded automatically for all specimens on the second and final days of exposure. Both cathodic and anodic polarization curves were recorded on the controls at about weekly intervals throughout the exposure period. The polarizing current was varied from zero to a suitable value by linear increments of voltage from a 10-turn voltage divider, shunted across a 12-v storage battery (fig. 2) and driven by a synchronous motor. The rate of polarization could be adjusted by the resistor $R$, the total polarizing time usually being about $20 \mathrm{~min}$.

The specimen under current control was protected with current from a $22.5-\mathrm{v}$ heavy duty dry battery in order that any change in potential of the specimen would make no appreciable change in the current. A series resistance was used for adjusting the current.

The circuit used for controlling the specimen potential at $-0.77 \mathrm{v}$ (free of $I R$ ) is shown in figure 3 . It utilizes the bridge circuit just described in conjunction with an electronic balancing unit used previously [2]. The control voltage, A, was adjusted to a value equal to one-half the difference between the potential of the zinc reference electrode and the protective potential for steel. Although the balancing unit was very sensitive to a potential difference across its terminals PS, the accuracy with which the potential of the specimen was actually maintained was obviously also dependent upon two other factors, namely: the stability of the potential of the zinc rod and the actual electrolytic resistance between the specimen and the zinc rod which was presumably balanced out by the variable resistance $\mathrm{X}$. These two factors did change, but the changes were gradual and were not difficult to cope with. Nevertheless, they did limit the accuracy of the potential measurements to perhaps $\pm 20 \mathrm{mv}$. The applied current was continuously recorded by $\mathrm{R}$ (fig. 3 ).

Figure 4 shows the circuit used for controlling potential at $-0.77 \mathrm{v}$ (including $I R$ ). It is the same as figure 3, except for the elimination of the bridge circuit. Control voltage $\mathrm{A}$ was adjusted to a value equal to the difference in potential between the zinc electrode and the protective potential for steel. Control accuracy here depended chiefly on the stability of the zinc potential and was about \pm 10 mv.

Currents and potentials were measured daily or less frequently. First, in addition to continuously recording the applied current to the specimen held 


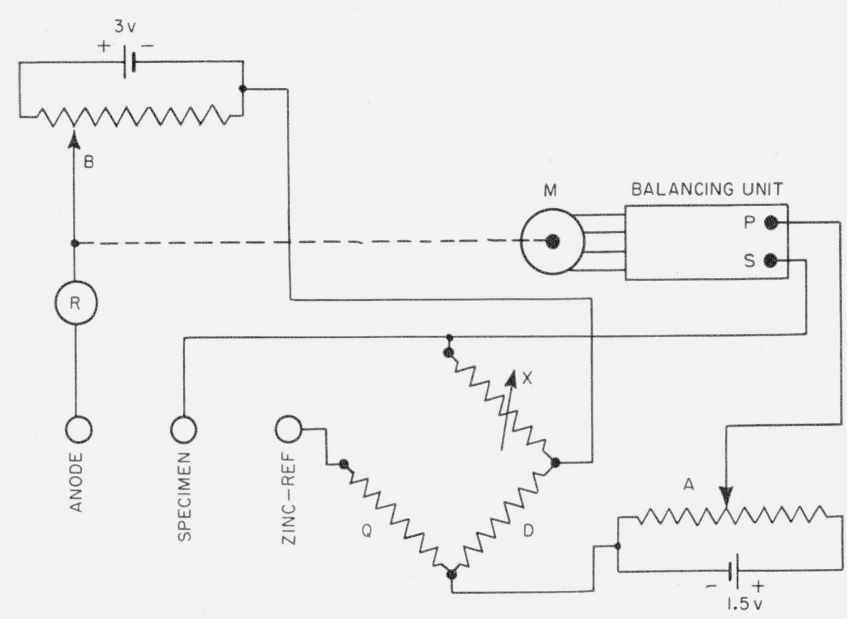

Figure 3. Potential control circuit and bridge circuit for balancing out the IR drop between the specimen and the associated zinc reference electrode.

The control voltage, A, was based on the protective potential of the specimen and on the potential of the zinc referred to saturated calomel.

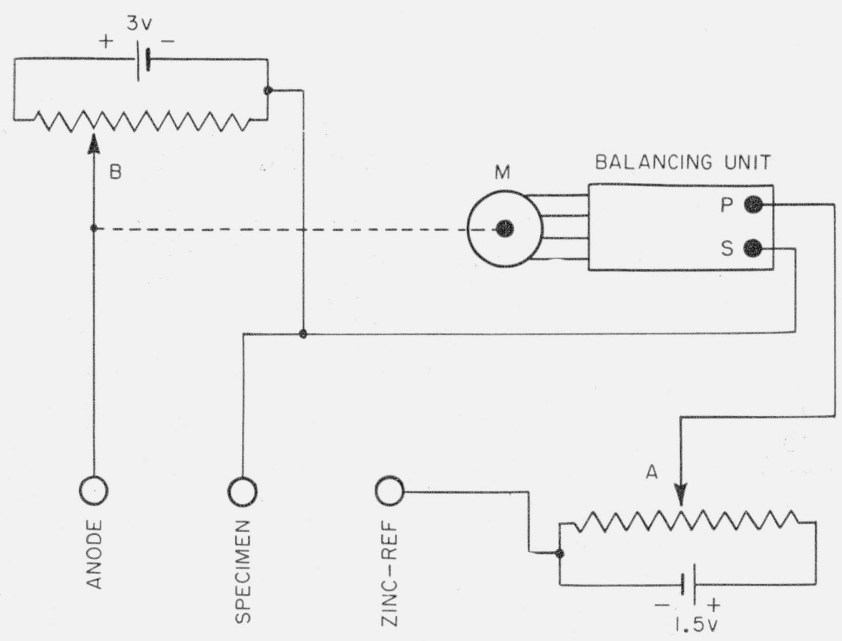

Figure 4. Potential control circuit used on the specimen where the IR drop between it and the zinc reference electrode was included.

The control voltage, A, was based on the protective potential of the specimen and on the potential of the associated zinc referred to saturated calomel.

at $-0.77 \mathrm{~V}$ (free of $I R$ ), currents were measured with an indicating milliameter inserted without interrupting the circuits. Next, potentials between the specimens and the zinc electrodes were measured with an indicating potentiometer, $I R$ drops caused by applied currents being included. This was followed by measuring the same potentials (without $I R)$ by use of the bridge circuit as previously described. Finally, the potentials of the zinc rods were measured with reference to a saturated calomel half-cell. The potentials of the specimens were then converted to the saturated calomel scale and adjustments were made on the control potentiometers, if necessary.

\section{Data and Discussion}

For the first two days of exposure all specimens were allowed to corrode freely. On the second day, cathodic polarization curves were obtained on one of the controls and on the three specimens subsequently to be placed under cathodic protection. At this time, an anodic polarization curve was also obtained on the same control, with substantially no polarization in evidence. The cathodic curves are shown in figure 5, plotted on semilogarithmic coordinate paper in order to aid in estimating the change-in-slope point (hereafter designated as $I_{p}$ ) indicated by the intersecting straight lines. Similarly, figure 6 shows the cathodic polarization curves obtained on control specimen No. 1 at intervals throughout the exposure period. Those for control specimen No. 2 were similar. Hereafter, the currents from these curves and all other measured currents are expressed as current densities in milliameters per square feet.

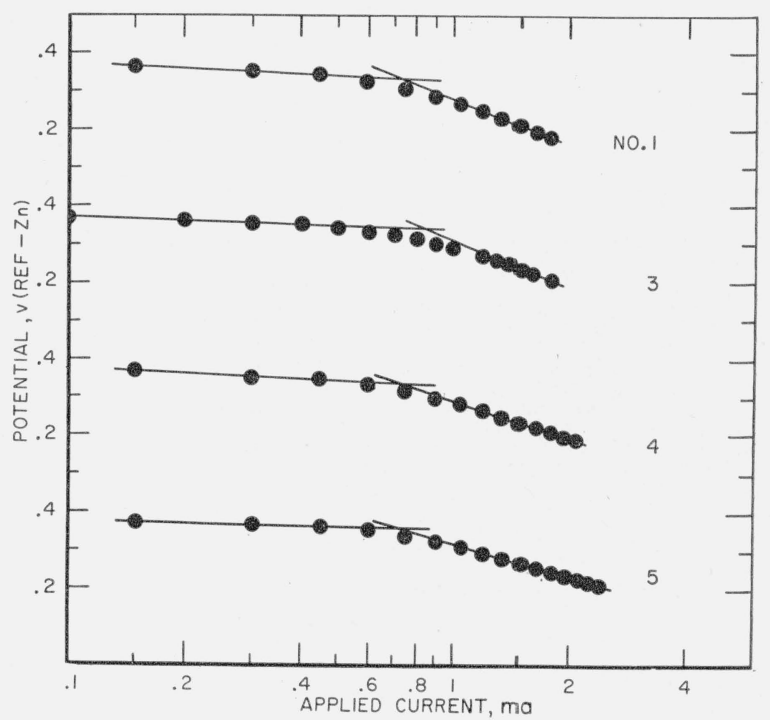

FIgURE 5. Cathodic polarization data for steel specimens, obtained on the second day of exposure, transferred from recorded charts to semilogarithmic coordinate paper.

One milliampere is equivalent to $6 \mathrm{ma} / \mathrm{ft}^{2}$ After the second day, specimen No. 1 was allowed to corrode freely, except when obtaining polarization data, and protective currents were applied to specimens Nos. 3,4 , and 5 .

Currents and potentials measured on the specimens throughout the 61-day exposure period are shown in figure 7 . Figure 8 is similar except that potentials include the $I R$ drops, and the potentials of the control specimens are omitted. Specimen No. 3 is the one where current alone was regarded as the protective criterion. The initial current applied to specimen No. 3 was the value shown by the polarization curve (fig. 5), and subsequent adjustments of current were based on the average of currents, $I_{p}$, observed on the control specimens Nos. 1 and 2 . 


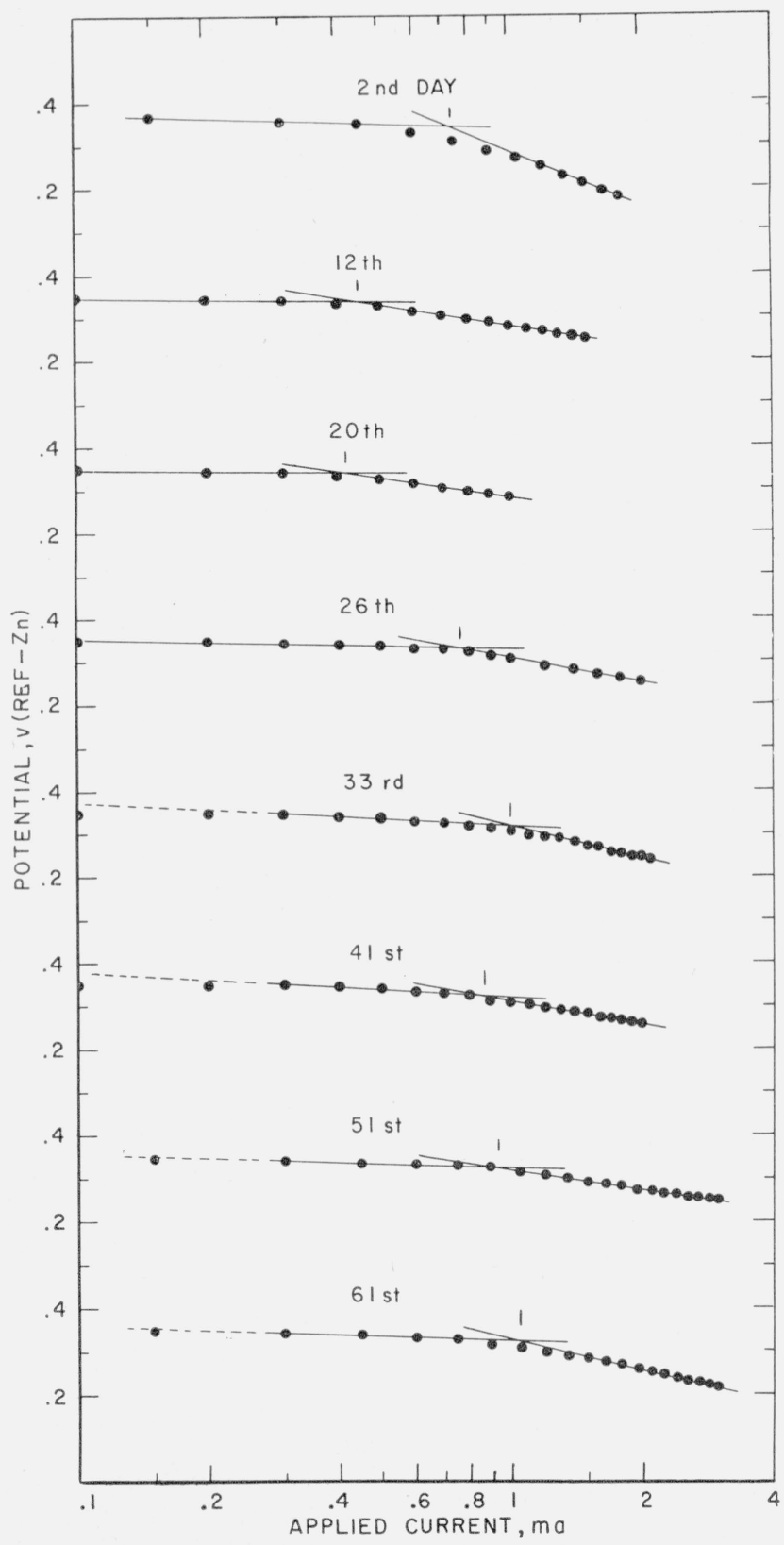

FIgURE 6. Cathodic polarization curves of control specimen No. 1 at intervals during the exposure period.

One milliampere is equivalent to $6 \mathrm{ma} / \mathrm{ft}^{2}$

From the 4th day onward, specimen No. 4 was controlled at $-0.77 \mathrm{v}$ (free of $I R$ ) and at the same time specimen No. 5 was placed under control at $-0.77 \mathrm{v}$ (including $I R$ ). Currents applied between the $2 \mathrm{~d}$ and 4 th days were estimated to produce the desired effects without control.

In figures 7 and 8, two values of current or potential for any one specimen on the same day means that adjustments were made. For example, in the case of specimen No. 3, except after the 49th day, the applied current was changed to conform with the polarizing currents, $I_{p}$, measured on the con- trols. However, the resultant changes in potential on that specimen were not measured until the following day or later. When adjusting the potential of specimen No. 4, the control was usually set at $-0.78 \mathrm{v}$, thus allowing a $10-\mathrm{mv}$ margin of safety. In fact, some control difficulties were experienced around the 27th day when for a period of about 7 days the control was even set at a somewhat more negative potential. The changes in applied current resulting from such changes in the potential adjustment were measured the same day as shown in figures 7 and 8. A mechanical failure in the control equipment caused specimen No. 4 to be without applied current from the 44th to 46th day. When the trouble was discovered on the 46th day, the potential measured -0.62 v. Before putting the controller back into operation, a cathodic polarization curve was obtained on specimen No. 4 which curve revealed that $4.2 \mathrm{ma} / \mathrm{ft}^{2}$ was required for protection. This agreed reasonably well with the values of applied current required for the following 6 days, except for a short time immediately after making adjustments in potential.

After the $22 \mathrm{~d}$ day of exposure, the polarization on specimen No. 3 began to decrease and the current applied to specimen No. 4 started to increase. It may also be observed (fig. 7) that a few davs later, the current to specimen No. 5 began to increase, vet polarization on No. 5 gradually kept falling. On the 26th day, cathodic polarization curves of the controls showed that more current, $I_{p}$, was necessary for protection and consequently the current to specimen No. 3 was increased accordingly. Subsequent values of current, $I_{p}$, were even larger, yet the potential of specimen No. 3 continued to become less negative until, on the 49th day of exposure, it was decided to arbitrarily increase the current as shown. Even at this high current density $\left(9.5 \mathrm{ma} / \mathrm{ft}^{2}\right)$, maintained for the remainder of exposure, only once did the potential approach $-0.77 \mathrm{v}$.

The foregoing trend of increasing current requirements is not consistent with the results of previous studies $[1,2]$ wherein the current required for cathodic protection usually diminished and leveled off as time of exposure increased. In the previous studies in low-resistivity environments, the corrosion reactions usually closely approached cathodic control. The protective currents ordinarily were equal to or slightly larger (not over $20 \%$ larger) than the corrosion currents. The results obtained in the present investigation (table 1) provide an explanation for this divergence. The corrosion current, calculated from the weight losses, is equivalent to a current density of $1.5 \mathrm{ma} / \mathrm{ft}^{2}$. A mean-current density of $4.2 \mathrm{ma} / \mathrm{ft}^{2}$ was required to protect specimen No. 4 at -0.77 v. This protective current is in fair agreement with the mean currents, $I_{p}$, from the cathodic polarization curves of the controls. As the current necessary for protection is "about threetimes the magnitude of the corrosion current, the corrosion reaction was either under anodic control [6] or a type of control equivalent to anodic control caused by high resistance at the anodic areas. That 


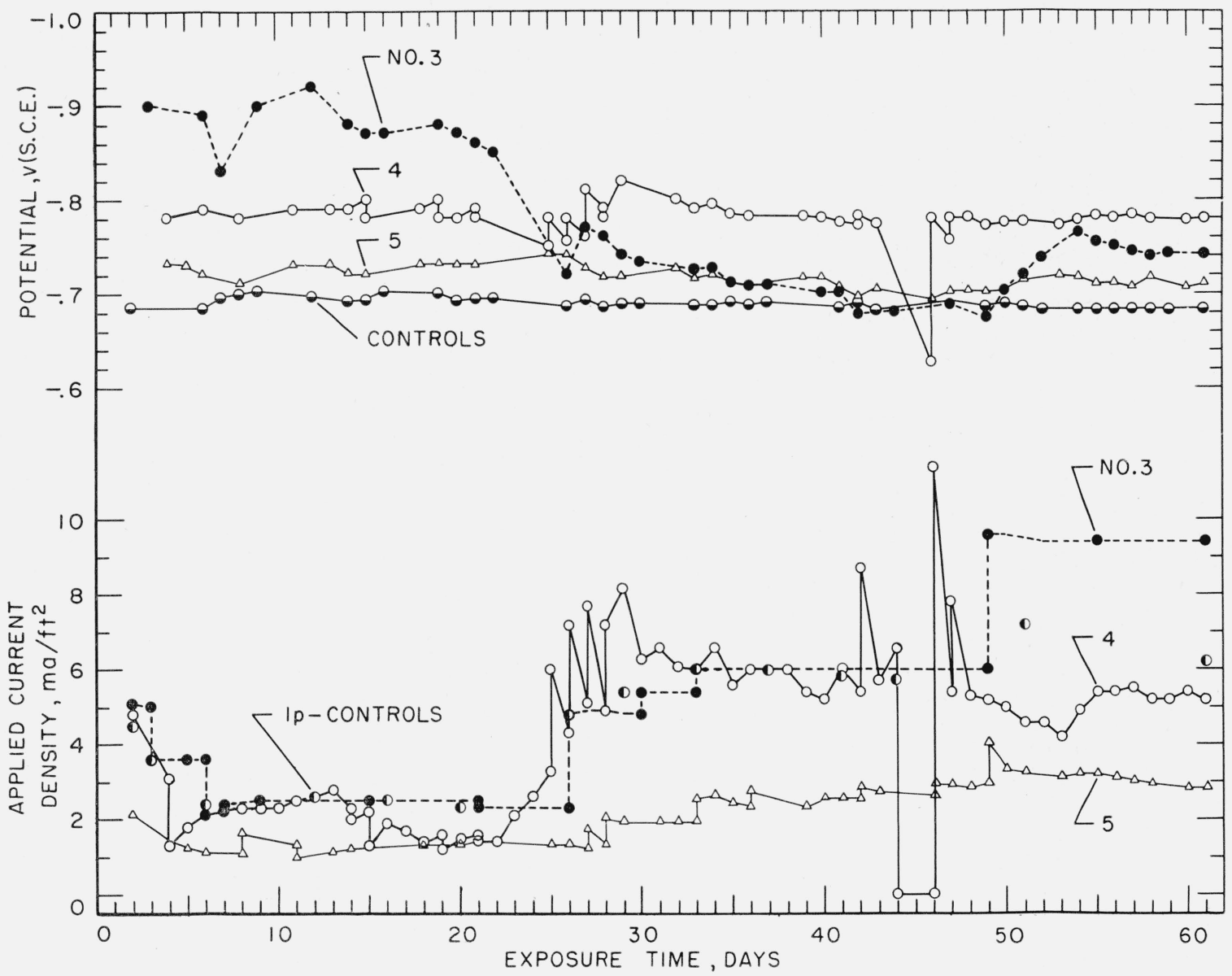

FIGURE 7. Relationship between potential (no IR) and applied current density for different degrees of cathodic protection on specimens Nos. 3, 4, and 5. S.C.E.= saturated calomel electrode.

lp is the protective current requirement averaged for control specimens Nos. 1 and 2 based on cathodic polarization curves; No. 3 specimen except after 49 th day, constant current conforms with lp; No. 4 specimen, variable current based on controlled potential $-0.77 \mathrm{v}$ (no $I R$ ); No. 5 specimen, variable eurrent based on controlled potential $-0.77 \mathrm{v}$ (including $I R$ ).

one condition or the other probably prevailed is supported by the anodic polarization curves (not shown) on the controls which were obtained the same days following cathodic polarization. The anodic curves in the beginning of the exposure period were indicative of cathodic control in that there was very little or no polarization. Later, polarization occurred and the break (change-in-slope) appeared in the anodic curves at currents of about the same magnitude as the cathodic currents, $I_{p}$. Finally, during the latter half of the exposure period the anodic curves revealed breaks at currents smaller than $I_{p}$. Thus, while the current necessary for cathodic protection increased as the exposure time lengthened, the anodic currents, presumably required to stop local action, became smaller.

The weight losses of specimens Nos. 3, 4, and 5 shown in the table have been adjusted for the time the applied currents were off, namely: 2 days for each of specimens Nos. 3 and 5, and 4 days for specimen No. 4. The adjustments were made on a proportionate basis of the control weight losses. One might conclude that the degree of protection achieved on specimen No. 4 was less than would have been expected, as this specimen was protected at a potential equivalent to $-0.85 \mathrm{v}$ free of $I R$ with reference to the more familiar $\mathrm{Cu}-\mathrm{CuSO}_{4}$ electrode. However, the measured potentials at best were only average values and in the $20,000 \mathrm{ohm}-\mathrm{cm}$ soil, because of current distribution difficulties, the potentials on some areas of the exposed surface might not have been at the protective level. Also, the adjustments made in weight losses are actually rather conservative. In the case of specimen No. 4, had the adjustment for the current off periods been based on weight losses calculated from the polarization curves, the degree of protection would have been about 76 percent.

Under the environmental conditions, a comparison of the data pertaining to specimens Nos. 3 and 4 shows the importance of maintaining polarization at the protective potential level if the goal is complete protection. Figure 7 shows that, during more than half of the exposure period, the potential of specimen No. 3 was less negative than $-0.77 \mathrm{v}$ even though the mean current (table 1) applied to specimen No. 


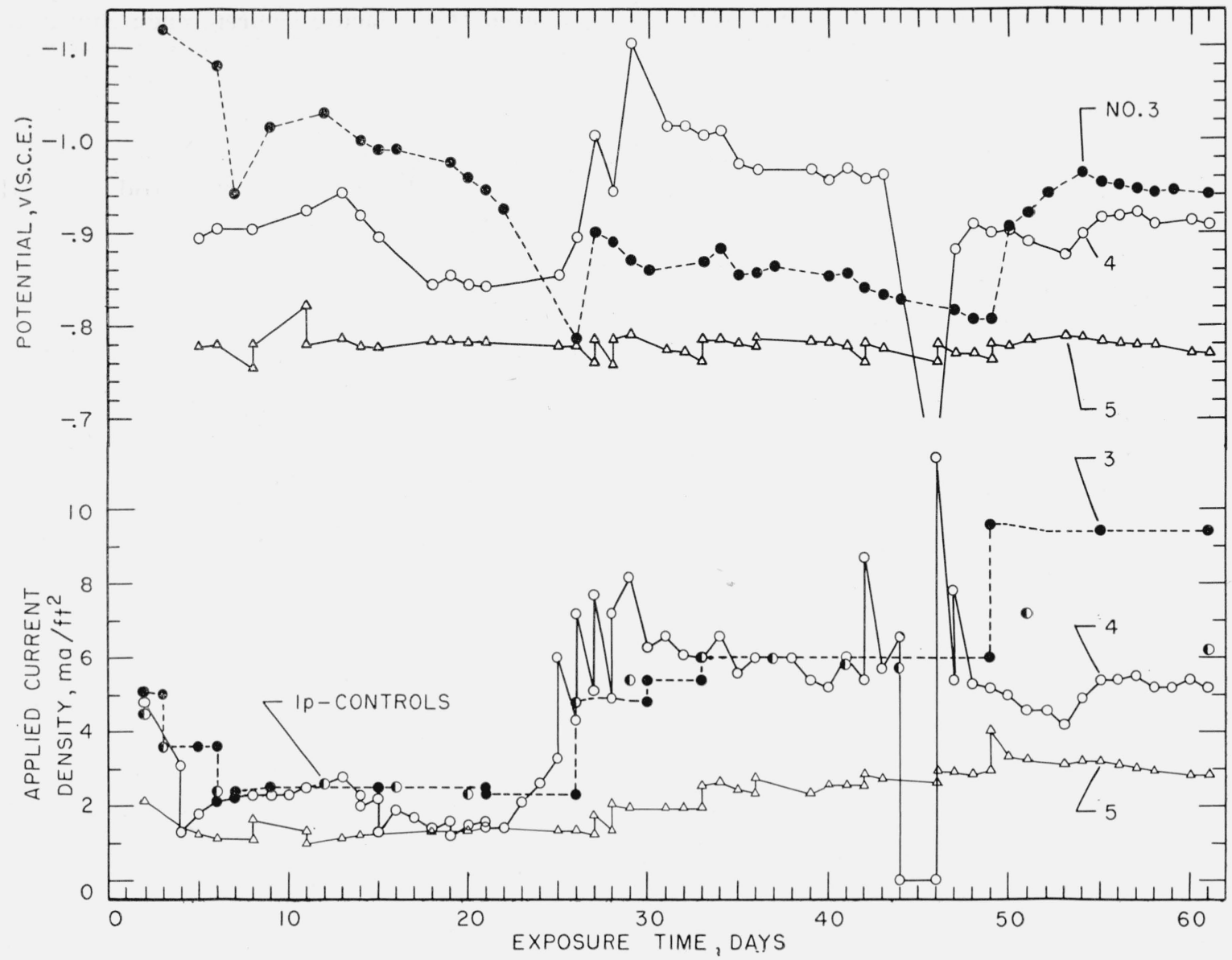

FIGURE 8. Same as figure \%, except that all potentials include IR drop, and the potentials of the controls are omitted.

TABLE 1. Steel specimens exposed for two months to a high resistivity $(\rho=20,000 \mathrm{ohm}-\mathrm{cm})$ soil

\begin{tabular}{|c|c|c|c|c|c|c|c|c|c|c|c|c|c|c|c|c|c|c|c|}
\hline \multirow{4}{*}{$\begin{array}{c}\text { Speci- } \\
\text { men } \\
\text { No. }\end{array}$} & \multirow{4}{*}{$\begin{array}{c}\text { Protective } \\
\text { criterion }\end{array}$} & \multicolumn{9}{|c|}{ Cathodic polarization curve } & \multicolumn{6}{|c|}{ Potential of specimen } & \multirow{4}{*}{$\begin{array}{l}\text { Corro- } \\
\text { sion a } \\
\text { current } \\
\quad \text { I }\end{array}$} & \multirow{4}{*}{$\begin{array}{l}\text { Weightb } \\
\text { loss of } \\
\text { speci- } \\
\text { men } \\
61 \text { days }\end{array}$} & \multirow{4}{*}{$\begin{array}{l}\text { Effec- } \\
\text { tive- } \\
\text { ness } \\
\text { of pro- } \\
\text { tection }\end{array}$} \\
\hline & & \multicolumn{3}{|c|}{$\begin{array}{c}\text { Current at break, } \\
\text { Ip }\end{array}$} & \multicolumn{3}{|c|}{ Potential at break, $F_{a}$ d } & \multicolumn{3}{|c|}{$\begin{array}{c}\text { Protective current } \\
\text { to specimen }\end{array}$} & \multicolumn{3}{|c|}{ No IR } & \multicolumn{3}{|c|}{ Including $I R$} & & & \\
\hline & & \multicolumn{2}{|c|}{ Range } & \multirow{2}{*}{ Mean } & \multicolumn{2}{|c|}{ Range } & \multirow{2}{*}{ Mean } & \multicolumn{2}{|c|}{ Range } & \multirow{2}{*}{ Mean } & \multicolumn{2}{|c|}{ Range } & \multirow{2}{*}{ Mean } & \multicolumn{2}{|c|}{ Range } & \multirow{2}{*}{ Mean } & & & \\
\hline & & Min & $\operatorname{Max}$ & & Min & $\operatorname{Max}$ & & Min & Max & & Min & $\operatorname{Max}$ & & Min & Max & & & & \\
\hline & Control_...-. & $\begin{array}{c}m a / f t^{2} \\
2.1\end{array}$ & $\begin{array}{c}m a / f t^{2} \\
6.6\end{array}$ & $\begin{array}{c}m a / f t^{2} \\
4.6\end{array}$ & $\begin{array}{c}v \\
-0.695\end{array}$ & $\begin{array}{c}v \\
-0.730\end{array}$ & $\begin{array}{c}v \\
-0.710\end{array}$ & ma/ft ${ }^{2}$ & $m a / f t^{2}$ & ma/ft ${ }^{2}$ & $\begin{array}{c}v \\
-0.683\end{array}$ & $\begin{array}{c}v \\
-0.702\end{array}$ & $\begin{array}{c}v \\
-0.689\end{array}$ & $v$ & $v$ & $v$ & $\begin{array}{r}m a / f t^{2} \\
1.5\end{array}$ & $\begin{array}{l}m g \\
375\end{array}$ & $\%$ \\
\hline & Control_-_-- & 2.3 & 8.7 & 5.0 & -.710 & -.740 & -.721 & & & & -.683 & -.705 & -.689 & - $78=$ & & & 1.5 & 375 & \\
\hline 4 & Potential & 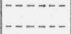 & (2) & & & 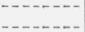 & 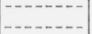 & $\begin{array}{r}2.1 \\
\cdot 1.2\end{array}$ & $\begin{array}{r}9.6 \\
11.4\end{array}$ & $\begin{array}{l}5.2 \\
4.2\end{array}$ & $\begin{array}{l}-.675 \\
\mathrm{e}-.750\end{array}$ & $\begin{array}{l}-.920 \\
-.820\end{array}$ & $\begin{array}{l}-.777 \\
-.778\end{array}$ & $\begin{array}{l}-0.785 \\
\mathrm{e}-.842\end{array}$ & $\begin{array}{l}-1.12 \\
-1.10\end{array}$ & $\begin{array}{r}-0.920 \\
-.914\end{array}$ & & $\begin{array}{l}161 \\
107\end{array}$ & $\begin{array}{l}57 \\
71\end{array}$ \\
\hline $5 \ldots$ & $\begin{array}{l}(\text { no } M R) \\
\text { Potential }\end{array}$ & & & & & & & & 4. 0 & 2.1 & -.693 & -.740 & -.717 & -.755 & -.823 & -.780 & & 182 & 51 \\
\hline & (with $I R$ ). & & & & & & & & & & & & & & & & & & \\
\hline
\end{tabular}

a Based on Faraday's law, $I=W / k t$, where $K=2.8938 \times 10^{-4} \mathrm{~g} /$ coulomb; $W=$ wt loss of controls (average grams); and $t=$ exposure time (seconds).

b Corrections made on specimens Nos. 3, 4, and 5 for initial freely corroding period and also for two intermediate days on specimen No. 4 when it was without protective current.

- Effectiveness of protection $=100(W c-W p) / W c$, where $W c=a v g$ wt loss of controls; and $W p=\mathrm{wt}$ loss of the protected specimens.

d $E_{a}=$ open-circuit potential of the anode (average).

e Specimen No. 4 was without protective current from the 44 th to the 46 th day when the potential (min) was actually $-0.627 \mathrm{v}$ on the 4 th day.

NOTE: Each specimen had an exposed area of 24 in. ${ }^{2}$ Potentials are referred to the saturated calomel electrode.

Specimens Nos. 1 and 2 were without cathodic protection.

Specimen No. 3 had current applied based on values of the current, $I_{p}$, averaged from polarization curves of specimens Nos. 1 and 2.

Specimen No. 4 was controlled at $-0.77 \mathrm{v}$ (no $I R$ ).

Specimen No. 5 was controlled at $-0.77 \mathrm{v}$ (including $I R$ ). 
3 was equal to or greater than that applied to No. 4. Thus, current density alone cannot be relied upon as a satisfactory criterion for cathodic protection.

Assuming that the inherent rates of corrosion on specimens Nos. 3 and 5 were about the same (cathodic polarization curves indicated that they were), it might be concluded that, based on the comparative applied current densities, the corrosion on specimen No. 5 was more economically controlled than that on specimen No. 3. Although more than twice as much current was applied to specimen No. 3, only a slightly better degree of protection resulted. On the other hand, the data also bring out the fact that any benefits of $I R$ drop while cathodically protecting a bare surface must be examined with caution. The degree of protection on specimen No. 5 was considerably less than that obtained on specimen No. 4, which received only a fair degree of protection, even though the $I R$ drop was not included in the controlled protective potential. Potential values which include $I R$ drops can be very misleading, as shown by figure 8 and the data in the table. In the case of specimen No. 5 (table 1), based on the mean control potential $(-0.689 \mathrm{v})$, the mean potential change $(91$ $\mathrm{mv})$, caused by the protective current, to the potential $-0.78 \mathrm{v}$ (including $I R$ ) was comprised of only $28 \mathrm{mv}$ attributable to polarization.

The data pertaining to specimen No. 5 also lead to questions concerning the proper positioning of the reference electrode. It is recognized that, in a theoretical consideration of the potential criterion for cathodic protection, the $I R$ drop in the cathodic area of a corrosion cell reduces the cathodic polarization required to fulfill the protective criterion, i.e., polarization to the open-circuit potential of the anode. The benefits of $I R$ drop (with reference to current flow to bare surfaces) resulting from applied currents to cathodic areas have been very ably demonstrated by Miller [7], Sudrabin [8], and others. Miller made measurements in a wet clay of about $1,000 \mathrm{ohm}-\mathrm{cm}$ resistivity. He showed that the cathode (a rusty iron pipe) of a galvanic cell need not be polarized to the open-circuit potential of the anode (a bright iron pipe) in order to reduce the galvanic current to zero. The additive effect of the IR drop within the cathodic branch was made very apparent. Miller showed that the open-circuit anode potential criterion was fulfilled when the reference electrode was placed directly over the anode or when placed in a remote position so as to include all of the cathodic $I R$ drop. However, Miller also recognized the possibility that his tests did not necessarily duplicate all actual conditions existing on a pipeline which presumably contains innumerable corrosion cells on its surface. Using a 22,000 ohm-cm resistivity water environment, Sudrabin demonstrated that the open-circuit anode potential (peculiar to the conditions) while the protective current was flowing, was indicative of complete protection if the reference electrode was placed directly over the anode or away from the cathode sufficiently far to include $I R$ drop within the boundary of the corrosion cell. He also showed that placing the reference electrode inside of the cell boundary resulted in excessive protective current but positioning it outside of the cell boundary resulted in insufficient protection. Sudrabin found that spacial factors, relative to the anodes and cathodes of a corrosion cell, control the correct location for the reference electrode and that these factors become more significant as the resistivity of the electrolyte is increased.

Measurements made in the laboratory at the National Bureau of Standards have shown that geometric factors should be given consideration when placing the reference electrode for potential measurements while cathodically protecting bare structures [9].

In the laboratory experiments described in this paper, it appeared as though the corrosion cells on the surface of the steel tubes had small dimensions and consequently any beneficial cathodic $I R$ drops must have been close to the metal surface. Were this not so, all the specimens would have received a better degree of protection. If most corrosion underground can be attributed to local action, and there is evidence that it can $[10,11]$, the inclusion of any $I R$ drop must be evaluated with understanding. It might be well to interject the thought brought out by Sudrabin [8] that the location of the reference electrode is not so critical when a highly resistive coating separates the bare metal surface from the corrosive environment.

\section{Summary}

The external surfaces of low-carbon steel specimens, in the form of tubes, were exposed for a period of 2 months in the laboratory to a soil having a resistivity of about $20,000 \mathrm{ohm}-\mathrm{cm}$.

There were five specimens, two of which were used as freely corroding controls and also for obtaining polarization data at approximately weekly intervals throughout the exposure period while the other three specimens had protective currents applied continuously. Periodically adjusted current was applied to one of the three on the basis of average values of current from the cathodic polarization curves obtained on the controls. Variable current was applied to each of the other two specimens based on the controlled potential $-0.77 \mathrm{v}$ referred to the saturated calomel half-cell. The control of the two specimens held at $-0.77 \mathrm{v}$ differed in that for one specimen the protective potential included the $I R$ drop caused by the protective current between the specimen and a reference electrode (a zinc rod) while the other specimen was controlled without including this $I R$ drop.

During the 2-month period of exposure a change occurred from a cathodic type of corrosion control to an anodic type or a type equivalent to anodic, seemingly caused by high resistance of the anodic areas on the specimens. This was evidenced by the characteristics of the cathodic and the anodic polarization curves of the controls, by increasing currents required for protection at the controlled potentials, 
and finally by the ratio of the value of protective current to the corrosion current.

The best degree of protection was achieved on the specimen controlled at $-0.77 \mathrm{v}$ (free of $I R$ drop). The other two specimens were protected to a lesser degree because of insufficient polarization. As in previous laboratory studies at the Bureau, the data show that cathodic polarization curves are a means for measuring the current required for cathodic protection but that the degree of protection being achieved is indicated best by changes in potential resulting from polarization.

The data show that $I R$ drop included in a potential reading (indicative of protection) can be very misleading, especially when bare iron or steel is exposed to a high-resistivity environment.

The author thanks Mr. E. A. Anderson, New Jersey Zinc Company, for furnishing the high-purity zinc rods used in the experiments.

\section{References}

[1] W. J. Schwerdtfeger and O. N. McDorman, Potential and current requirements for the cathodic protection of steel in soils, J. Research NBS 47, 104 (1951) RP2233; Corrosion 8, 391 (1952).
[2] W. J. Schwerdtfeger, Current and potential relations for the cathodic protection of steel in salt water, J. Research NBS 60, 153 (1958) RP2833; Corrosion 14, 446t (Oct. 1958).

[3] L. P. Sudrabin and F. W. Ringer, Reply to discussion, Some observations on cathodic protection criteria, Corrosion 13, 836t (Dec. 1957).

[4] NACE Unit Comm. T-2C, Corrosion 13, 105 (Nov. 1957)

[5] H. D. Holler, Studies on galvanic couples 1. Measurement of electromotive force and internal resistance of cells during current flow, J. Electrochem. Soc. 97, 271 (Sept. 1950); Corrosion ' 52 (Feb. 1951)

[6] W. J. Schwerdtfeger and O. N. MeDorman, Measurement of the corrosion rate of a metal from its polarizing characteristics, J. Electrochem. Soc., 99, 407 (1952).

[7] M. C. Miller, Galvanic couples and cathodic protection, Petrol. Eng. (May 1946).

[8] L. P. Sudrabin, Some observations of calhodic protection potential criteria in localized pitting (A report of $\mathrm{T}-2 \mathrm{C}$ on minimum current requirements for cathodic protection NACE Pub. 54-2) Corrosion 10, 232 (Aug. 1954).

[9] W. J. Schwerdtfeger and Irving A. Denison, Geometric factors in electrical measurements relating to corrosion and its prevention, J. Research NBS 54, 61 (1955) RP2566; Corrosion 11, 25 (Oct. 1955).

[10] Gordon N. Scott, An aspect of the pipe-to-soil potential and related measurements, NBS Soil Corrosion Conference 1943 (unpublished). Excerpts of this paper appeared in Gas (Feb. 1944).

[11] K. H. Logan, S. P. Ewing, and I. A. Denison, Soil corrosion testing, Symposium on Corrosion Testing Proc., ASTM (1937).

Washington, D.C.

(Paper 63C1-4) 